\title{
Importance of interchangeability for urban guided transport equipment
}

\author{
Latifa Furlan • Hartmut Schmidt
}

Received: 9 December 2009/Accepted: 27 December 2010/Published online: 14 June 2011

(C) The Author(s) 2011. This article is published with open access at SpringerLink.com

\begin{abstract}
The European Union wishes to develop strategies to increase the number of urban transport passengers over the coming years. Urban transport is the key transport mode for the decrease of congestion, pollution, energy consumption and limitation of land use by transport in cities. Urban areas are the drivers of the European economy. This implication of European authorities rests on the means mobilised in European research projects. These research projects aim at conceiving the common model of the future safe and interchangeable guided transport systems in Europe and highlights the problems related to the harmonisation of the steps of safety certification of such systems. Therefore, the concept of interchangeability ((UGTMS), (MODURBAN)), is important and, it means that system components can be produced from any suppliers and replaced without any substantial change in functionality or performance. It also allows the system to adapt to technology evolutions without significant modifications to its architecture. The main barriers for reaching these objectives are the complexity of the existing systems, the diversity of national legislation and the lack of international standards. The common model of this framework
\end{abstract}

\footnotetext{
L. Furlan $(\bowtie)$

Accredited certifier on safety,

29 rue Georges Pompidou,

59810, Lesquin, France

e-mail: latifa_furlan@yahoo.fr

H. Schmidt

Freelancer for Consulting Companies in Germany,

Innsbrucker Strasse 42,

10825, Berlin, Germany

e-mail: hartmut.h.schmidt@gmx.de
}

is needed to open the competitive market for urban transport.

Keywords Interchangeability - Urban guided transport . Harmonisation · Safety · European Union

\section{Introduction}

Transport reliability, availability, efficiency and safety are some of the basic conditions for the growth of quality of life in the European Union $[3,10]$.

High quality transport is needed for strengthening the competitiveness of the European economy. This covers transport of persons as well as transport of goods.

This need has encouraged European institutions to set up several research projects. These European projects mainly aim to design, develop and try-out an open and innovating architecture with common model and interfaces for transport systems. Now, each country applies their own safety assessment, but it is also clear that the recent applications are assessed more and more taking into account the European standards [3-5].

As explain above, the interchangeability aims to harmonise interfaces for control-command, energy saving and access sub-assemblies for metro and light rail rolling stock.

The objective of this work is to highlight the importance to have a common model of safety for urban guided transport equipment.

This article can be loosely divided into 4 parts. We establish in the first part, the different types of transport and, in the second part, the needed framework for interchangeability. The third part describes the safety common model identified following the first elements of 
similarities for UGT (Urban Guided Transport). In the last part, the different aspects of interchangeability are introduced.

\section{Different types of transports}

On the transport market there are different sectors. The road sector is especially successful. But this causes large problems of congestion, pollution and land-use. A better use of the different types of transport through creation of the framework for improving competition between the transport modes is necessary.

\subsection{Railway transport}

Railway transport has a long tradition of being operated by state-owned companies. The influence of national and even regional or local characteristics cultivated by political interests has brought a wide diversity of differences in the fields of legislation, technologies; operational \& service, practises and safety \& security strategies.

The European efforts for harmonising the legislation and standardisation in the field of international, national and regional railway transport are the starting conditions for more competition and success of railway transport in the future. The efforts of different R\&D - projects like ERTMS (ERTMS), MODTRAIN (MODTRAIN) and others, as well as the 3 "railway - packages" (RAILWAY PACKAGES) are paving the way for the future growth of railway transport. They are basic for better interoperability of railways on the different national railway networks and future European High-speed Corridors TEN-T (TEN T). Competition between the different international and national railway operators (private, public or Public - Private Partnership), both for passenger transport as well as for transport of goods, is a precondition for the competition between road transport and railway transport. Long distance railway lines are now in competition with air transport.

\subsection{Urban guided transport (UGT)}

Urban Guided Transport (UGT) is a public transport system in an urban area with motorised vehicles operated on a guideway. This document deals especially with metrosystems, light rail— systems and tram - systems.

Because of special needs (different to those of the railways) for service (customer needs), operation and technology, Urban Guided Transport will use only a small part of the benefits supported by the European Commission for the Railways.

UGT systems are an integrated part of public transport in urban areas with a very high demand by citizens, operated with high frequency, in peak hours. They are the backbones of transport in large cities.

The European Commission supports the development and the competitiveness of UGT by different R\&D projects: UGTMS [17], MODURBAN [13], URBAN Track (URBAN TRACK) and others, as well as by funding of infrastructure investments in cities. Because of the strong influence of national laws and local specifics the different UGT systems have "tailor-made" infrastructures, technologies and are not comparable.

Metro systems are isolated, and therefore, there was no need for interoperability between different systems. Even for tram systems the vehicles normally do not fit to different infrastructures. But that means that customers travelling in different or even foreign cities have to "learn" the rules of the local operators.

The operators are mostly national or even regional or local because of the lack of standards. The development of equipment for the different systems is very costly and the existing situation is a barrier for free competition among the suppliers.

\section{The needed framework for interchangeability}

The goal, in short-term, is to design through European research projects, bases on the control/command system with strong constraints : the interchangeability and interoperability of materials in the transborder zones. The launching on the market of such systems is subject to strong requirements of safety $[7,8]$.

Interoperability is the ability of a transport network to operate safely different trains on interoperable infrastructures, communicating the necessary control-command data with the trackside (without major change in functionality or performance). This ability supposes that all regulations, technical and operational conditions are met in compliance with the requirements applicable for a given grade of automation of the line. Interoperability also means that the sidetrack is able to work with trains, which are equipped at a smaller automation level.

Interchangeability allows the replacement of one component supplied by one industry provider by the same component supplied by another provider.

Even if interoperability is generally not needed in the networks of UGT systems, interchangeability of components is a key for the development of the European market for the supply industry.

There have to be agreements on cross - acceptance of nationally-certified products for the whole market in Europe.

To open the different national (or even local) markets there has to be a common European framework of legislation and standardisation. 
At the moment, the equipment of the local systems is certified on the basis of very differently fixed national laws and directives. The decisions on certifications are made by local authorities. The responsibilities are neither on European nor on national levels. Because of all these reasons it is quite difficult to harmonize the requirements on the European level. Therefore, in the European R\&D projects UGTMS - Urban Guided Transport Management System [17] and MODURBAN - Modular Urban Guided Rail Systems [13] the first attempts were made to fix the standards for the calculation concerning the safety and quality levels.

\subsection{The key barriers for cross acceptance of UGT components}

Cross acceptance means: the status achieved by a product that has been accepted by one Authority on the basis of the relevant European Standards and is acceptable to other Authorities without the necessity for further assessment [5].

In parallel with the MODURBAN project, international standardisation of general system functional requirements were started by the International Electrotechnical Commission (IEC).

The international Norm: IEC 62290-1 UGTMS, "Urban guided transport management and command/ control systems - Part 1: System principles and fundamental concepts", was completed in the year 2006. The Working Group "WG 40" is now in the discussion on IEC 62290-2 UGTMS. "Urban Guided Transport Management and Command/Control systems - Part 2: Functional Specifications".

These standards will be keys for the development of products with cross-border acceptance in Europe.

But the main barrier will still exist. The European countries have different approaches for the certification of the safety of the integrated Urban Guided Transport systems and their components. That is for new systems, extensions of existing systems and for all new developed components used as replacement parts or for the upgrading of existing systems.

\section{Toward a common safety model for UGT}

\subsection{The safety principles}

The CENELEC standards EN 50126 [3], and EN 50129 [5] define "safety" as the freedom from unacceptable levels of risk. So, the old question: "how safe is safe enough?" is reduced to the question: "what levels of risk are acceptable?". EN 50126 recommends that a generally accepted principle should be used and introduces the three risk acceptance principles, GAME, ALARP and MEM:

\subsubsection{The French safety principle [6]}

GAME (Globalement Au Moins Equivalent)

According to Decree STPG 2003-425/9 May 2003

(sécurité des transports publics guidés)

Main articles are:

- article ${ }^{\circ} 3$ states that all modification of guided transport is considered as essential if safety demonstration is modified

- article ${ }^{\circ} 5$ GAME principle is compulsory:

(GAME means "Globalement Au Moins Equivalent""All new guided transport system must offer a level of risk globally at least as good as that offered by any equivalent existing system").

According to Decree STPG 2003-425/9 May 2003 the following elements are requested for the Safety Approval Process:

DEFINITION CASE DD: "Dossier de Definition"; (definition case) is the first step to initialise a dialog between the person in charge of work and the safety authority. It establishes the legal framework proposing the preliminary safety and quality plans and the main characteristics (functional, technical, the general Safety targets). It may be considered as a concept submission to the safety authority who accept it or not.

PRELIMINARY SAFETY CASE DPS: "Dossier Préliminaire de Sécurité"; (Preliminary Safety Case) specifies in detail the Safety targets, the requirements, the methods and the principles used to reach them. A Preliminary Hazards Analysis is included.

An independent safety assessor report delivered by an independent Assessor Body is added to the file. The Safety Authority approves the DPS, the starting point of work is given by supplying the funds.

SAFETY CASE DS: "Dossier de Sécurité"; Safety Case, this final and most important document, includes the DD and the updated DPS, and has to demonstrate that the requirements described in the DPS are fulfilled.

\subsubsection{The UK safety principle [18]}

Responsibility for the regulation of health and safety on the railways and other guided transport systems was transferred from the Health and Safety Commission (HSC) and Health 
and Safety Executive (HSE) to the Office of Rail Regulation (ORR) on 1 April 2006.

The Health and Safety at Work etc. Act 1974 (HSWA) (Updates 1992 and 1999) is the principal health and safety law in Great Britain. It places general duties on employers to ensure the health, safety and welfare at work of their employees and to conduct their undertaking so that persons not in their employment are not exposed to risks to their health and safety. Employers must ensure "As Low As Reasonably Practicable" that these duties are met. This qualification is abbreviated to "ALARP"- Assess and reduce risk so far as is reasonably practicable.

The ALARP principle (As Low As Reasonably Practicable) is described in it:

Between the region of unacceptable risk and the region of broadly accepted risk, there is a tolerability region where risk is undertaken only if a benefit is desired and where each risk must be made as low as reasonably practicable (see Fig. 1 below).

\subsubsection{The German safety principle [2, 16]}

In Germany, the federal (Bundes Land) level concentrates the legislative framework.

The German approval process presents two different legal frameworks:

- the first concerns heavy metropolitan railways (regional lines or commuter lines) generally considered as railway applications which are under the law AEG [1] with the Regulation named EBO (Federal Regulation for Construction \& Operation of RailwaysEisenbahn-Bau-und Betriebsordnung);

- the second concerns urban guided transport which do not interface with railway lines. These networks, are covered by the law PBefG [14] with the Regulation named BOStrab (Federal Regulation for Construction \& Operation of Urban Guided Transport Systems- Verordnung über den Bau - und Betrieb von Straßenbahnen).

MEM (Minimum Endogenous Mortality) The individual risk due to a particular technical system must not exceed
$2 * 10-4$ fatalities/person*year of the minimum endogenous mortality.

This principle is not used because there is no direct relation to railways.

In practice, use the following values is allowed:

- $\mathrm{R} 1<-10-5$ deaths per person per year,

- $\mathrm{R} 2<-10-4$ serious injuries per person per year,

- $\quad \mathrm{R} 3<-10-3$ slight injuries per person per year,

For systems which could produce a large number of deaths, it is also necessary to take into account a "coefficient of aversion" which reduces the acceptable risk.

MGS principle The German MGS (Mindestens Gleiche Sicherheit - at least the same level of safety) is based on the EBO and is generally the same as the GAME principle.

\subsection{SIL (Safety Integrity Level)}

In the international standards $[3,5,12]$ the level of safety of a system assuring functions of safety is defined, in a qualitative way, according to 4 classes:

Level 4, the highest level, applies to the systems assuring the most critical functions.

Level 3, can apply to posts assuring functions of safety on lines used for transport;

Level 2, applies to systems assuring functions of control which, for example, can be used in situations degraded by the developer to raise a condition of safety;

Level 1, applies to systems used in particular cases of help or maintenance.

When a system assures a function by no means connected to the safety, it is of SIL level 0.

The SIL's notion is particularly useful for computer systems, notably software, for which it is impossible to demonstrate the respect of an objective calculated for safety.

It is necessary to note that the SIL of a system is determined by the experts of the network according to the criticality of the functions assured by the system.

Fig. 1 ALARP principle

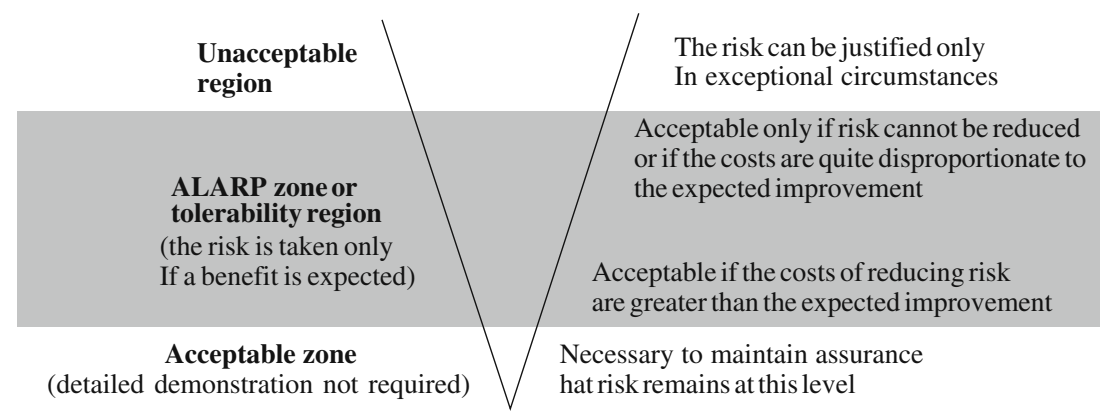




\subsection{Evaluation of safety}

The most critical problem of cross-border acceptance is the fact that the existing standards give a discretion margin for the quantification of safety. This means that in special cases it depends on the characteristics needed for the users whether the safety case can be certified or not.

Taking into account the different national philosophies in Europe this means that there should be only one model (without gaps) for the calculation of safety cases to obtain values that have to be accepted in all European countries.

\subsection{National French, German, UK, Hungarian approval processes}

The traditional authorisation, regulation and certification processes in different European countries for urban transport safety system have been already identified and analysed $[9,11]$.

We have analysed the responsibility allocation between public authorities, certification bodies, assessors, operators and system suppliers.

After this analysis, we have proposed a questionnaire to obtain all the types of regulation and certification processes in the other European countries.

From this analysis, we can conclude that there are significant similarities and essential differences.

There is, for example, a certain convergence in the use of European standards and safety principles (GAME or ALARP). It has also been demonstrated that the document of reference between the different key players, either during the design phase or the start up phase, is the safety case.

However, there are quite different procedures in the European countries but the procedures are not the main problem.

\subsection{Cross acceptance as one condition}

for interchangeability

The key to solving the central problem for cross-acceptance and interchangeability of certified systems and components produced by different European suppliers is to agree on safety standards and their approval model at the European level. By means of this, the European market can be opened for all products certified by national or even local authorities.

The example of the railways shows that the cross acceptance of certified vehicles has started. On the basis of the three railway packages after a long time of negotiations the first step for the Railways was done on 16th April, 2008 by French and German authorities signing a contract to simplify the cross-acceptance of
Railway vehicles of both countries. By means of this, the costs for certification of railway vehicles in the respective countries, France or Germany, will be reduced by $70 \%[15]$.

\section{Additional different aspects of interchangeability}

The different laws, regulations and standards on international, European and national levels for UGT systems and even the components obstruct interchangeability additionally. Mechanical and electrical equipments are normally used for 30 years. Electronic equipment has mainly a life cycle of 8 to 10 years. This also causes problems for interchangeability.

\subsection{Equipment of infrastructure}

Infrastructure of UGT systems is determined by the laws, regulations and standards for UGT systems (constructions and buildings, mechanics, electrical equipment, electronic devices...). The equipment is very often a combination of different demands and components may have mechanical, electrical and electronic parts.

The determinations have to be respected in combination with the safety principles. This means a high complexity for the evaluation of the equipment of the infrastructure.

In reality most of the components of infrastructure are internationally accepted.

But there is still the barrier for the acceptance of certifications on command/control systems and their components installed in infrastructure.

\subsection{Vehicles}

Because of the different generations of vehicles and the different supplier-specific components and interfaces of the vehicles, there is a severe difficulty for the interchangeability of vehicles and trains, even between different lines within one network, if the equipment for the parts of the command/control system installed in the infrastructure and of the vehicles for coupling, for the onboard parts of command/control, communicationsystems, passenger - information and other onboard systems, are not especially constructed for the aspect of interchangeability.

This problem exists even for vehicles of different generations produced by a single supplier. It has a great importance if there are different products of different suppliers and different generations.

The interchangeability of vehicles and trains is an important requirement for the optimisation of operational processes. 


\subsection{Equipment of vehicles}

The different components of a vehicle have different lifecycles. Especially when there is a change of components or even an upgrade of the command/control system, there should be the opportunity for using onboard - components of different suppliers.

The complexity of the integration of new components and the overall responsibility for the safety of the vehicles means that there are large barriers for interchangeability of the equipment of vehicles.

5.4 Mechanical and electrical equipment, maintenance and spare parts

The interchangeability of mechanical and electrical wayside and on-board equipment can be achieved more easily. But even for this part of the market the diversity of products is high. The development of components using new materials, and the necessity to integrate new parts in existing solutions, cause problems for maintenance and demands in many case-specific certifications.

Nevertheless, the different local solutions existing are still barriers for the competition between even national suppliers.

\subsection{Electronic equipment, maintenance and spare parts}

The Integrated solutions for wayside and on-board equipment with the requirements on Reliability, Availability and Maintainability have brought new components where mainly mechanical, electrical and electronic elements work together. This consequently causes the problem of Software solutions with very often no open interfaces. Electronic hardware components very often have a lower life - cycle than the mechanical and electrical ones. This demands additional flexibility for maintenance and replacement of parts. The complexity of maintenance (plug and play) and the storage of spare parts make interchangeability of products of different suppliers almost impossible to achieve.

\section{Conclusion}

The safety assessment and approval of new or altered systems are an essential condition to protect people and the environment from dangers arising from the operation of guided transport systems.

As explain above, this study shows the complexity of necessary preconditions for the opening of the market for the European UGT system supply industry as a part of cost - efficiency of products and necessary for competitive structures. The example of the railway market shows that there can be success.

The main key for interchangeability is the European standardisation for the calculation of the safety-case in association with an agreement between the stakeholders of urban guided transport.

It will be necessary to progressively find a common model for national regulation of member states. But all the other described barriers should not be under estimated.

Open Access This article is distributed under the terms of the Creative Commons Attribution License which permits any use, distribution and reproduction in any medium, provided the original author(s) and source are credited.

\section{References}

1. AEG (1993) German Law for the operation of Railways [“Allgemeines Eisenbahngesetz 27. Dezember 1993 (BGBl. I S. 2378 (2396) $(1994,2439)]$

2. BOStrab, 1987. German Federal Regulations on the construction and operation of light rail transit systems issued 11 December 1987 translation of Verordnung uber den Bau und Betrieb des Stassenbahnen, prepared by G.H. Hafter, OBE, Rail Transport Consultant formerly Director of Mechanical Engineering, London Undergrounffd Ltd.

3. CENELEC EN 50126, (2000) Railway Applications - The Specification and demonstration of Reliability, Availability, Maintainability and Safety (RAMS)

4. CENELEC EN 50128, (2001) Railway Applications- Software for Railway Control and Protection Systems

5. CENELEC EN 50129, (2003) Railway Applications- Communications, signalling and processing systems - Safety related Electronic Systems for Signalling

6. Décret STPG, (2003) Décret n 425 du 9 mai 2003- sécurité des transports publics guidés

7. Deliverable D10, (2005) Conformity assessment, Human factor impact, Guidelines for FRS - UGTMS Project

8. Deliverable D92, (2008) Second conformity assessment, guidelines for functional and technical prescriptions - MODURBAN Project

9. Deliverable NERA, (2000) Safety regulation and standards for european railways, report for DG Energy and Transport

10. Directive (1996) Directive 96/48/CE of 23 July on the interoperability of the trans-European high-speed rail system

11. Furlan L, Benard V, Duquenne N (2007) Towards an European Certification process for the safety of urban guided transport systems, 15th Symposium EURNEX - Zel 2007, Zilina, Slovac Republic

12. IEC 61508-1 (2002). International Standard - Functional safety of electrical/electronic/programmable electronic safety-related systems, Part 1: General requirements

13. MODURBAN - Modular Urban Guided Rail Systems $-6^{\text {th }}$ Framework Program

14. PBefG (1990) German law for the transportation of persons in urban areas["Personenbeförderungsgesetz 8. August 1990 (BGB1. I S. 1690)] 
15. Press release (2008) Eisenbahn Bundes Amt, EBA, of the German

16. TÜV (2002) Rheinland Berlin Brandenburg Safety and Quality "Trained on the Future, Services for Guided Transport Systems"

17. UGTMS - Urban Guided Transport Management System $-5^{\text {th }}$ Framework Program

18. YELLOW BOOK 3, (2005) Volumes 1 and 2, fundamentals and Guidance, published by railtrack on behalf of the UK rail industry

\section{Web sites}

19. ERTMS, http://www.ertms.com/

20. MODTRAIN, http://www.modtrain.com/

21. RailwayPackages, http://ec.europa.eu/transport/rail/countries/lu/ mne_en.htm

22. TENT, http://ec.europa.eu/ten/transport/agency/index_en.htm

23. URBANTRACK, http://www.urbantrack.eu/ 